\title{
Integrating Quizlet and Socrative into Teaching Vocabulary
}

\author{
Hang Pham \\ Lao Cai High School for the Gifted, Lao Cai Province
}

\begin{abstract}
Rote memorization is boring and ineffective for EFL students as it provides no context for usage.
\end{abstract} Despite the drawbacks, many teachers still use this method to teach vocabulary. This workshop will present two fun technology tools, Quizlet and Socrative, to help students learn vocabulary in context and monitor their progress.

\section{Session Description}

How to teach vocabulary in an interesting and memorable way is a question EFL professionals have been trying to answer for a long time. According to Laufer \& Hill (2000), in order to acquire unknown words, students should access a dictionary with various look-up options such as pictorial and verbal cues. However, traditional methods of teaching and learning vocabulary often lack these options. Participants at this presentation will be introduced to two technology tools to teach vocabulary interactively and track students’ progress efficiently. The presentation begins with some unique features of Quizlet and Socrative. The participants are first introduced to different ways of using Quizlet to (a) enhance students’ grasp of pronunciation, (b) promote language practice everywhere (at home, in class, on the go, etc.), (c) generate interactive games to help students study their course content, and (d) create paper handouts, flash cards, or game materials. Socrative, another user-friendly technology tool, helps teachers design and assess student learning via personal mobile devices. The presenter will involve the audience in designing their own activities using the two applications. Ultimately, the participants will discuss the pros and cons of using these practical technology tools and will brainstorm ways to apply them in various EFL classroom contexts. This presentation will be useful for EFL instructors in disadvantaged areas with a lack of opportunities to stay updated, or ESP teachers who are simply interested in integrating technology into their teaching. 


\section{References}

Laufer, B., \& Hill, M. (2000). What lexical information do L2 learners select in a CALL dictionary and how does it affect word retention? Language Learning and Technology, 3, 58-76.

Back to Table of Contents 